\title{
Direito Penal e COVID-19 no espaço lusófono
}

\author{
Criminal Law and COVID-19 in the lusophone world \\ Derecho Penal y COVID-19 en el espacio lusofono
}

Inês Fernandes Godinho',2

\begin{abstract}
Resumo
Objetivo: convocar as normas penais relevantes para o contexto pandémico dos ordenamentos jurídicos tomados como referência (Portugal, Brasil, Angola e Região Administrativa Especial de Macau) a fim de aferir das vantagens e desvantagens dos respetivos modelos. Metodologia: através de uma análise comparativa dos diferentes modelos, foi utilizado o método dedutivo para asserção da possível vantagem ou desvantagem, tendo em conta a função do Direito Penal. Resultados: as normas penais mais relevantes, em especial, o crime de desobediência, comum a todos os ordenamentos, acabam por assumir a natureza de normas penais em branco. Conclusão: tendo o contexto pandémico evidenciado a importância de uma efetiva tutela penal da saúde pública, a mesma deve ser feita através de um modelo que melhor cumpra a função de garantia do direito penal.
\end{abstract}

\section{Palavras-chave}

Pandemia. COVID-19. Direito Penal. Saúde Pública. Análise comparativa.

\begin{abstract}
Objective: to identify the relevant criminal law norms for the pandemic context of the legal systems taken as reference (Portugal, Brazil, Angola and Macao Special Administrative Region) in order to assess the advantages and disadvantages of the respective models. Methods: through a comparative analysis of the different models, the deductive method was used to assert the possible advantage or disadvantage, taking into account the function of Criminal Law. Results: the most relevant criminal norms, in particular, the crime of disobedience, common to all ordinances, end up assuming the nature of blank criminal norms. Conclusion: having the pandemic context highlighted the importance of an effective criminal protection of public health, it should be done through a model that better fulfills the function of guarantee of criminal law.
\end{abstract}

\section{Keywords}

Pandemic. COVID-19. Criminal Law. Public Health. Comparative analysis.

\section{Resumen}

Objetivo: identificar las leyes penales relevantes para el contexto pandémico de los sistemas jurídicos tomados como referencia (Portugal, Brasil, Angola y la Región Administrativa Especial de Macao) para evaluar las ventajas y desventajas de los respectivos modelos. Metodología: a través de un análisis comparativo de los diferentes modelos, se utilizó el

\footnotetext{
${ }^{1}$ Doutora em Direito, Universidade de Coimbra, Coimbra, Portugal; Professora Associada, Faculdade de Direito e Ciência Política, Universidade Lusófona do Porto, Porto, Portugal. https://orcid.org/0000-0003-0823-6985. Email: ifgodinho@netcabo.pt

$\frac{2}{2}$ Este artigo faz parte do projeto "Responsabilidade em Saúde Pública no Mundo Lusófono: Fazendo Justiça durante e além da Emergência da Covid" - WHO ERC number - (CERC.0079/ HEG 70) - da iniciativa da OMS/Ética em Epidemia e foi financiada por FCDO/Wellcome Grant 214711/Z/18/Z
} 
método deductivo para afirmar la posible ventaja o desventaja, teniendo en cuenta la función del derecho penal. Resultados: las normas penales más relevantes, en particular, el delito de desobediencia, común a todas las ordenanzas, acaban asumiendo la naturaleza de normas penales en blanco. Conclusión: habiendo evidenciado el contexto pandémico la importancia de una efectiva tutela penal de la salud pública, la misma debe hacerse a través de un modelo que cumpla mejor la función de garantía del derecho penal.

\section{Palabras clave}

Pandemia. COVID-19. Derecho Penal. Salud pública. Análisis comparativo.

\section{Introdução}

A crise instalada globalmente devido à pandemia COVID-19 afetou todos os campos da vida em sociedade, pública e privada, e, sem exceção, também a área da justiça penal, tanto no patamar da sua aplicação, com as limitações derivadas das restrições sanitárias, como no próprio recurso ao direito sancionatório para cumprimento de medidas sanitárias impostas.

Tem sido visível, em termos globais, uma dualidade entre a proteção da saúde pública e o respeito pelas liberdades fundamentais dos cidadãos. Com efeito, tem-se assistido à imposição de medidas restritivas - com maior ou menor intensidade - com vista à contenção do vírus que assola o mundo, e que vão desde o uso de máscara, ao distanciamento social, à quarentena, ao confinamento, até ao completo lockdown.

Em tempos de pandemia, o direito sancionatório é um dos instrumentos ao dispor dos Estados, quer pelo papel dissuasor que poderá representar, quer pela vertente repressiva de comportamentos que possam pôr em causa as medidas impostas pelos Estados para combater a pandemia. Assim, o percurso assentará em uma perspetiva que contemple tanto o direito vigente, como eventuais normas sancionatórias criadas em virtude da pandemia, tendo em conta as disposições relevantes do direito penal de quatro ordenamentos jurídicos do espaço lusófono que aqui tomamos como referência, designadamente, Portugal, Brasil, Angola e a Região Administrativa Especial de Macau.

\section{Direito penal e combate à pandemia COVID-19}

O direito penal representa o mais alto grau de ingerência do Estado na vida dos cidadãos (1, p. 130), daí que se deva pugnar por um direito penal mínimo. E como epítome de um direito penal mínimo, existe um corpo de princípios que limitam a intervenção do direito penal e das suas normas, por forma a garantir que este somente é chamado a intervir quando a proteção de certo e determinado bem jurídico não possa ser lograda de outro modo (ultima ratio). 


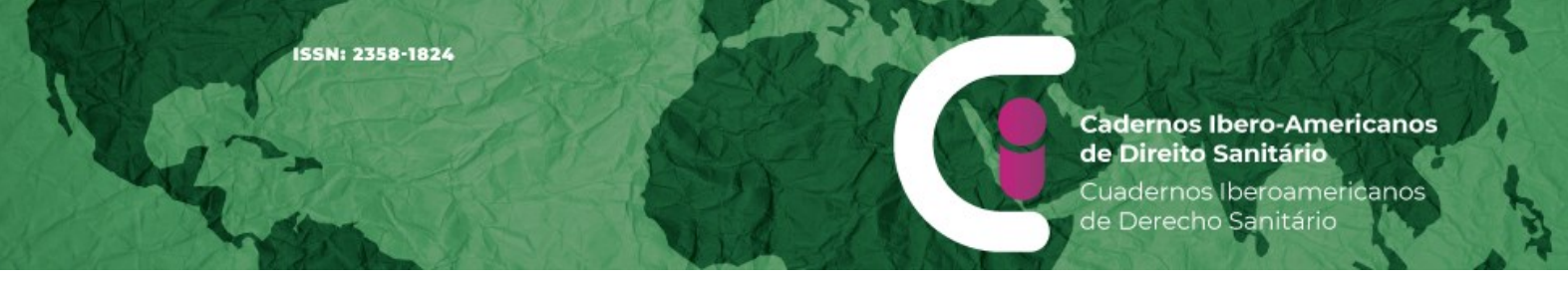

No âmbito do direito penal, poderíamos dizer que o justo se afere no patamar da norma penal e da protecção dos bens jurídicos (função do direito penal) e que o direito penal justo se prende com a sua aplicação (penas). Todavia, não apenas o recorte dos bens jurídico-penais (fragmentaridade de $1^{\circ} \mathrm{grau}$ ) pode ser barómetro de justiça no direito penal. Também o modo ou a amplitude como esses bens jurídico-penais são protegidos (fragmentaridade de $2^{\circ}$ grau) refrata o justo (2, p. 150 e s.). Por outras palavras, pretendese que o direito penal proteja os bens jurídicos que permitam a manutenção da convivência comunitária, bens esses que vão sendo historicamente definidos e construídos através das valorações que em cada momento são consideradas representarem uma ética comum (3, p. 47). Neste sentido, o direito penal é também o reflexo de cada época, legitimando apenas aquelas normas que protejam bens jurídicos que se afirmem como verdadeiros objetos do direito penal, por serem dignos de proteção e merecedores de tutela penal $(4$, p. 173) $(5$, p. 76).

E ainda que estas considerações de índole geral possam ser tidas como adquiridas, no momento em que muitos Estados vivem, por virtude da pandemia, verdadeiros estados de exceção constitucional, importa relembrar dois aspetos fundamentais: por um lado, o direito penal não é vacina para o vírus e, em segundo lugar, o direito penal e sancionatório não pode transformar-se na prima ratio de combate à pandemia.

Em um tempo em que milhões de cidadãos veem os seus direitos e liberdades afetados pelas medidas restritivas impostas, é essencial não perder o horizonte compreensivo em que se move (ou deve mover) o direito penal e a tendência centrípeta do poder repressivo do Estado.

Neste sentido, procuraremos sistematizar as principais normas penais convocáveis, considerando a existência de normas específicas para a proteção da saúde pública ${ }^{3}$, tendo em conta o atual contexto pandémico ${ }^{4}$, analisando as implicações dos diferentes modelos identificados.

\section{Legislação penal e saúde pública}

Em Portugal, o Código Penal tinha, até à reforma de 1995, no âmbito dos crimes de perigo comum, crimes especificamente dirigidos à proteção da saúde pública ${ }^{5}$. Entre esses

\footnotetext{
${ }^{3}$ Face ao enquadramento do presente texto, não se tomará como bem jurídico de referência a vida ou a integridade física. ${ }^{4}$ Não serão, pois, consideradas normas que, mesmo protegendo a saúde pública, não se relacionem com as atuais circunstâncias - p. ex., poluição de água potável ou abate clandestino -, ou que apenas reflexamente protejam a saúde pública (p. ex., tráfico de droga).

${ }^{5}$ Que correspondiam à então Secção II do Capítulo III.
} 
crimes existia - com maior relevo para a perspetiva aqui adotada - o crime de propagação de doença contagiosa (art. $270^{\circ}$ do Código Penal de 1982) ${ }^{6}$. Não obstante, com a reforma de 1995, foi eliminada esta secção II do Capítulo II, deixando de existir uma secção específica no Código relativa à saúde pública. Os crimes dela constantes passaram a estar integrados, em geral, nos crimes de perigo comum, tendo sido alterada a sua redação e retirada a sua autonomia incriminatória. Ou seja, por um lado, diversas condutas passaram a estar integradas em incriminações "conjuntas" e, por outro lado, o bem jurídico tutelado foi alterado, através de uma exigência no tipo de um perigo concreto para a vida ou para a integridade física. Dito de outro modo, com a reforma de 1995 deixou de existir no Código Penal português a dicotomia entre a tutela da saúde individual e a tutela da saúde pública.

Assim, ainda que atualmente possam considerar-se convocáveis os artigos $282^{\circ}$ (Corrupção de substâncias alimentares ou medicinais) e $283^{\circ}$ (Propagação de doença, alteração de análise ou de receituário) do Código Penal, a verdade é que a tutela penal da saúde pública sofreu uma degradação ${ }^{7}$. Ou seja, não existem incriminações que possam ser diretamente mobilizadas no atual contexto pandémico, como protegendo qua tale a saúde pública $^{8}$, uma vez que é doutrina maioritária que, face à exigência de um perigo concreto para a vida ou a integridade física, o bem jurídico tutelado por ambos os tipos legais de crime é a vida e a integridade física (7, p. 999) (8, p. 1007-1008) (9, p. 1008, p. 1010).

Nesta sequência, o art. $283^{\circ}$ do Código Penal português, que (também) inclui a incriminação de propagação de doença, abrange todas as doenças contagiosas, desde que adequadas à produção de um perigo para a vida ou um perigo grave para a integridade física (8, p. 1008).

Considerando as diferentes incriminações em causa nos artigos $282^{\circ}$ e $283^{\circ}$ do Código Penal português, podemos encontrar nos Códigos Penais de Angola e do Brasil crimes análogos aos previstos naqueles artigos (arts. $286^{\circ}$ e $287^{\circ}$ do Código Penal angolano ou $\mathrm{o}$ art. $273^{\circ}$ do Código Penal brasileiro, este último, relativo à corrupção de produto destinado a fins terapêuticos ou medicinais), mas ainda que possamos encontrar

\footnotetext{
${ }^{6}$ Os crimes contra a saúde pública incluíam também, na redação original do Código Penal de 1982 , o crime de contaminação e envenenamento de água (art. $269^{\circ}$ ), o crime de difusão de epizootias (art. $271^{\circ}$ ), o crime de deterioração de alimentos destinados a animais (art. $272^{\circ}$ ), o crime de corrupção de substâncias alimentares ou para fins medicinais $\left(\right.$ art. $\left.273^{\circ}\right)$, o crime de alteração de análises (art. $274^{\circ}$ ), o crime de alteração receituário (art. $275^{\circ}$ ) e o crime de recusa de facultativo (art. $276^{\circ}$ ).

${ }^{7}$ No Decreto-Lei n. ${ }^{\circ}$ 28/84, de 20 de Janeiro, relativo às infrações antieconómicas e contra a saúde pública, o único crime claramente orientado para a proteção da saúde pública é o abate clandestino (art. $22^{\circ}$ do Decreto-Lei n. ${ }^{\circ} 28 / 84$ ).

${ }^{8}$ Ainda que, logo em Abril de 2020, Maria Fernanda Palma se tenha pronunciado a favor da consideração da saúde pública como bem jurídico protegido no crime de propagação de doença (6).
} 
semelhanças com o Código Penal português, o traço comum aos Códigos Penais angolano e brasileiro, que os distingue do português, é uma tutela especificamente orientada para a saúde pública, em qualquer um deles.

Na verdade, o Código Penal angolano inclui ainda o crime de contágio de doença grave $\left(\operatorname{art.~} 206^{\circ}\right)$, apesar de o mesmo estar sistematicamente incluído em capítulo não direcionado para a saúde pública ${ }^{9}$.

No ordenamento jurídico brasileiro existe uma diferença que importa assinalar. Com efeito, neste ordenamento jurídico mantém-se patente a dicotomia da tutela da saúde individual e da saúde pública, contando o Código Penal brasileiro com um capítulo específico de crimes contra a saúde pública, ou seja, mantendo-se a tutela expressa deste bem jurídico no Código Penal. Mas, mais do que isso, este capítulo integra crimes diretamente relacionados com emergências de saúde pública derivadas de doenças infectocontagiosas, ou seja, os crimes de epidemia (art. $267^{\circ}$ ), infração de medida sanitária preventiva $\left(268^{\circ}\right)$ e omissão de notificação de doença $\left(269^{\circ}\right)$.

Ainda que possamos encontrar redação idêntica aos artigos $282^{\circ}$ e $283^{\circ}$ do Código Penal português no Código Penal da Região Administrativa Especial de Macau (arts. $269^{\circ} \mathrm{e}$ $270^{\circ}$ ), a RAEM tem, no âmbito da Lei n. ${ }^{\circ}$ 2/2004 (Lei de prevenção, controlo e tratamento de doenças transmissíveis), uma incriminação específica para contextos epidémicos, designadamente o crime de infração de medida sanitária preventiva (art. $30^{\circ}$ ).

Um aspeto interessante, quanto à concretização da tutela penal da saúde pública, pode encontrar-se na análise entre as incriminações de infração de medida sanitária preventiva (art. $268^{\circ}$ do Código Penal brasileiro e art. $30^{\circ}$ da Lei n. ${ }^{\circ} 2 / 2004$ da RAEM) é que a sua diferente localização sistemática no ordenamento jurídico respetivo - Código Penal e legislação especial - vem a influenciar a construção do tipo legal de crime. Estando o art. $268^{\circ}$ previsto no Código Penal, encontra-se construído como uma norma penal em branco (11, p. 911), na medida em que as medidas sanitárias preventivas serão aquelas determinadas no momento respetivo pelo poder público, não estando, pois, especificadas. Inversamente, sendo o art. $30^{\circ}$ uma norma penal da Lei n. ${ }^{\circ} 2 / 2004^{10}(10)$, remete para as medidas sanitárias preventivas já previstas na própria Lei (Lei n. $\left.{ }^{\circ} 2 / 2004\right)$. Por outras

\footnotetext{
${ }^{9}$ Ou seja, encontra-se no capítulo da colocação de pessoas em perigo.

${ }^{10}$ Esta Lei (Lei n. $\left.{ }^{\circ} 2 / 2004\right)$, visando garantir a saúde pública e a prevenção, controlo e tratamento eficazes de doenças transmissíveis, através dos princípios da prevenção prioritária e do tratamento adequado (art. $1^{\circ}, \mathrm{n} .^{\circ} 1$ ), contém diversas medidas que podem ser aplicáveis em casos de surtos ou prevalência ou risco de surto ou prevalência de doença transmissível (arts. $14^{\circ}$, e $23^{\circ}$ a $2^{\circ}$ ), sendo que estabelece, para a violação dessas medidas e para a violação do preenchimento de declarações exigíveis (art. $10^{\circ}$ ) o crime de infracção de medida sanitária preventiva.
} 
palavras, ainda que, no ordenamento jurídico brasileiro, se mantenha a tutela penal efetiva da saúde pública - diversamente do que sucede no Código Penal português -, essa mesma tutela é parcialmente conseguida através de alguma indeterminação da norma penal, tanto mais complexa porquanto admite a competência concorrente da União, Estados e Municípios para a adoção de normas de contenção do coronavírus (11, p. 914).

Em termos punitivos ${ }^{11}$, , a moldura penal do art. $268^{\circ}$ do Código Penal brasileiro é fixa, ou seja, prevendo-se a detenção de um mês a um ano e multa, não existe uma graduação da pena consoante a importância ou gravidade da medida infringida, devendo depois tal ser apreciado na determinação da medida concreta da pena. No art. $30^{\circ}$ da Lei n. ${ }^{0} 2 / 2004$ vai existindo uma graduação da pena consoante a importância ou gravidade da medida sanitária infringida. Assim, por exemplo, a violação da medida de isolamento, restrição ou estabelecimento de condicionalismos ao movimento de pessoas de zonas específicas ou pertencentes a grupos específicos de risco de contágio de doenças transmissíveis (art. 25, n. ${ }^{\circ}$, al. 2), da Lei n. ${ }^{\circ}$ 2/2004) poderá ser punida com pena de prisão até 2 anos ou com pena de multa até 240 dias (art. $30^{\circ}$, al. 4), da Lei n. $2 / 2004$ ), enquanto quem violar medida de preenchimento de declaração específica atendendo à natureza e sintomas das doenças (art. $10^{\circ}$, n. $^{\circ} 2$, al. 1 ), da Lei n. ${ }^{\circ} 2 / 2004$ ) apenas poderá ser punido com pena de prisão até 6 meses ou com pena de multa até 60 dias (art. 30, al. 1), da Lei n. ${ }^{\circ} 2 / 2004$ ).

\section{Legislação penal e controlo da pandemia}

Uma das preocupações dos diferentes Estados tem sido o controlo da população, com vista a evitar a propagação do coronavírus. Nem todos os Estados tendo normas penais diretamente orientadas para a saúde pública, como visto no ponto precedente, é, todavia, comum a existência de incriminações destinadas a tutelar a ordem pública em sentido amplo.

Assim, um dos crimes que também tem conhecido forte expressão em tempos de pandemia é, justamente, o crime de desobediência, enquanto crime contra a autoridade pública.

O crime de desobediência simples é um crime que, em termos gerais, não implica qualquer violência ou coação, estando usualmente tipificado como uma falta à obediência

\footnotetext{
${ }^{11}$ Aqui não se considerando a agravação do art. $268^{\circ}$, $\S$ único, do Código Penal brasileiro e tendo apenas em conta a moldura penal de base.
} 
devida (12, p. 349) e protegendo, pois, a autonomia intencional do Estado (12, p. 350) (13, p. 177$)^{12}$.

O crime de desobediência pode incluir duas modalidades. Por um lado, existe a designada desobediência em sentido próprio, ou seja, quando um funcionário ou agente de autoridade emitirem e comunicarem (regularmente) ordem ou mandado legítimos - sob a forma de norma de conduta concreta (12, p. 354) -, cominando o seu incumprimento com a prática do ilícito (13, p. 179). Usualmente esta modalidade surge como modalidade subsidiária, ou mesmo com uma dupla subsidiariedade: apenas possível se não puder ser integrada como desobediência imprópria - ou seja, a partir de uma disposição legal - e se o incumprimento em causa não for sancionado por outra norma jurídica (12, p. 354) (13, p. 179). Por outro lado, encontra-se a denominada desobediência imprópria. Trata-se dos casos em que a cominação pelo crime de desobediência é feita por uma outra norma jurídica.

Não deixa de ser interessante que, atento este recorte do tipo de ilícito, usualmente integrando uma norma penal em branco, especialmente na modalidade da cominação, em que a incriminação atua como a consequência da violação da conduta típica prevista em outra legislação e que comina a sua violação com o crime de desobediência (13, p. 178), se tenha assistido a movimentos de descriminalização da desobediência (12, p. 349). E agora, em tendência inversa, atenta a necessidade de cumprimento das medidas sanitárias preventivas, a relevância deste crime tem conhecido alguma expansão.

O crime de desobediência encontra-se previsto nos diversos Códigos Penais dos ordenamentos jurídicos do espaço lusófono que aqui tomamos como referência.

Em Portugal, o crime de desobediência encontra-se consagrado no art. $348^{\circ}$ do Código Penal, prevendo as duas modalidades de desobediência, ou seja, a desobediência própria e a desobediência imprópria. Já o Código Penal brasileiro prevê a desobediência simples no art. $330^{\circ}$ do Código Penal, abrangendo o mesmo apenas a desobediência própria. Em Angola ${ }^{13}$, o art. $340^{\circ}$ do Código Penal inclui ambas as modalidades de desobediência. $\mathrm{O}$ art. $312^{\circ}$ do Código Penal da RAEM, de redação idêntica ao art. $348^{\circ}$ do Código Penal português, também prevê tanto a desobediência própria, como a desobediência imprópria. Os artigos $312^{\circ}$ do Código Penal da RAEM, $348^{\circ}$ do Código Penal português e $340^{\circ}$ do Código Penal angolano preveem ainda o crime de desobediência qualificada nos respetivos números 2 , sendo que, em todos eles, apenas se permite a

\footnotetext{
12 Paulo Pinto de Albuquerque considera que este crime protege a autonomia intencional do funcionário (9, p. 1103).

13 Faz-se referência ao Código Penal aprovado em 2020.
} 
qualificação da desobediência quando a mesma tenha sido cominada por disposição legal, i.e., não a admitindo nos casos de desobediência própria. O que, aliás, vai ao encontro do art. $330^{\circ}$ do Código Penal brasileiro, dado este, por apenas prever a desobediência própria, não admitir a desobediência qualificada.

Em termos de sanção, podemos encontrar algumas diferenças entre as diversas normas penais acima indicadas. Olhando para a desobediência simples, tanto o art. $312^{\circ}$ do Código Penal da RAEM, como o art. $348^{\circ}$ do Código Penal português preveem a pena de prisão até um ano ou pena de multa até 120 dias. Já o art. $340^{\circ}$ do Código Penal angolano prevê para a desobediência simples uma pena de prisão até 6 meses ou pena de multa até 60 dias, sancionando o art. $330^{\circ}$ do Código Penal brasileiro a desobediência simples com detenção, de 15 dias a 6 meses, e multa. Quanto à desobediência qualificada, a linha de diferença em termos de moldura penal identificada entre, de uma banda, o Código Penal angolano e, de outra banda, os Códigos Penais português e da RAEM, mantém-se, ou seja, enquanto estes punem a desobediência qualificada com pena de prisão até dois anos ou de multa até 240 dias, aquele pune a desobediência qualificada com pena de prisão até um ano ou de multa até 120 dias, sancionando, pois, a desobediência qualificada com a moldura penal com que é sancionada a desobediência simples em Portugal e na RAEM.

Além disso, em Portugal, foi ainda criado um crime de desobediência específico nos primórdios do "combate penal" à pandemia.

Com efeito, no início do estado de emergência em Portugal, o Decreto n. ${ }^{\circ} 2-A / 2020$, de 20 de Março ${ }^{14}$ começou por estabelecer um crime de desobediência específico para os casos de violação da obrigação de confinamento obrigatório (art. $3^{\circ}$ ), além da cominação, por crime de desobediência (art. $348^{\circ} \mathrm{CP}$ ), de um conjunto de outras situações, maxime, o encerramento de instalações e estabelecimentos, a suspensão de actividades no âmbito do comércio a retalho e da prestação de serviços (art. $32^{\circ}, \mathrm{n} .{ }^{\circ} 1$, al. b), do Decreto). Este modelo foi sendo mantido pelo Decreto n. ${ }^{\circ} 2-\mathrm{B} / 2020$, de 2 de Abril (arts. $3^{\circ}$ e $43^{\circ}$, n. $^{\circ} 1$, al. d)); e Decreto n. ${ }^{\circ} 2-\mathrm{C} / 2020$, de 17 de Abril (arts. $3^{\circ}$ e $46^{\circ}$, n. $^{\circ} 1$, al. d)).

Todavia, com a nova declaração, em 6 de Novembro de 2020, do estado de emergência em Portugal, abdicou-se do crime de desobediência específico constante dos Decretos $n .^{\circ} \mathrm{s} 2-\mathrm{A}, 2-\mathrm{B}$ e 2-C, acima referidos, voltando a recorrer-se à cominação por crime de desobediência (art. $12^{\circ}$, n. $^{\circ} 1$, al. b) do Decreto n. $8 / 2020$, de 8 de Novembro), recurso

\footnotetext{
${ }^{14}$ Que procedeu à regulação da primeira declaração de estado de emergência efetuada pelo Decreto do Presidente da República n. ${ }^{\circ}$ 14-A/2020, de 18 de Março.
} 
que se viria a manter nos decretos de regulamentação dos estados de emergência decretados pelo Presidente da República seguintes. O crime de desobediência encontra-se cominado, fundamentalmente, para a violação de confinamento obrigatório, para a violação da proibição de circulação na via pública e para a violação da limitação das atividades de estabelecimentos comerciais e serviços.

Havendo regime próprio na RAEM, o recurso ao crime de desobediência, nos termos feitos, por exemplo, no ordenamento jurídico português, não se mostra tão necessário.

Diferentemente, nos países em que não exista uma Lei como a Lei n. ${ }^{\circ}$ 2/2004 da RAEM, o recurso a esta via repressiva - mesmo quando existam crimes mais específicos para a protecção da saúde pública - tem sido o caminho seguido como forma de sancionar a violação de medidas sanitárias impostas no controlo e combate à COVID-19.

\section{Discussão de resultados}

Compulsando as duas linhas de análise - a tutela penal da saúde pública e o crime de desobediência -, verifica-se que, quanto à primeira linha, nos ordenamentos jurídicos tomados como referência existem duas situações que poderíamos identificar como os extremos opostos. Se, no ordenamento jurídico português podemos assistir a uma completa degradação da tutela penal da saúde pública ${ }^{15}$, no pólo oposto encontramos, no Código Penal brasileiro ${ }^{16}$, uma efetiva tutela penal da saúde pública, considerando a dimensão dinâmica que este bem jurídico tem vindo a assumir.

As dificuldades, neste último caso, podem prender-se com a construção típica de incriminações como a infração de medida sanitária preventiva, em que quando exista recurso a uma norma penal em branco - por oposição a uma integração em um diploma que especifica as medidas sanitárias, como acontece na RAEM - possam ser suscitadas questões de interpretação e aplicação da norma penal.

Por outro lado, e quanto à segunda linha de análise, existe, nos diversos ordenamentos jurídicos considerados, alguma semelhança, desde logo, na consagração do crime de desobediência.

Mas também aqui se vê que existem modelos de construção típica mais repressivos, maxime, em termos de sanção - Portugal e RAEM - do que outros (Brasil, Angola).

\footnotetext{
15 Como refere Susana Aires de Sousa, "não deixa de ser preocupante que, em Portugal, no ano de 2020, o reconhecimento penal dado à saúde pública se restrinja exclusivamente a uma dimensão sanitária (já sublinhada no séc. XVIII), por via da singular incriminação do abate clandestino prevista num diploma que remonta a 1984" (14).

${ }^{16}$ Com todo o simbolismo da respetiva integração no Código Penal.
} 
De notar ainda, em termos gerais, que também quanto a este crime - como no caso da infração de medida sanitária preventiva do Código Penal brasileiro - estamos perante uma norma penal em branco.

\section{Conclusões}

Em termos de legislação penal vigente, maxime, o Código Penal respectivo, pode observar-se uma grande semelhança quanto aos crimes de corrupção de substâncias medicinais e de propagação de doença, além da ordenação destes crimes como crimes de perigo comum e não como especificamente contra a saúde pública. Mas casos existem, como o Código Penal brasileiro, onde encontramos não só a especificação de um capítulo de crimes contra a saúde pública, como também tipos legais de crime concretamente orientados para situações epidémicas e pandémicas, ou a incriminação contida no art. $30^{\circ}$ da Lei n. ${ }^{\circ}$ 2/2004 da RAEM, especificamente orientada para estas situações.

Um aspeto interessante, em termos de direito sancionatório penal, é o aumento do recurso ao crime de desobediência, como modo de repressão do desrespeito de medidas de prevenção e combate à pandemia implementadas em estados de exceção. Em Portugal, por exemplo, em que tem sido feito recurso a estados de exceção - v.g., estados de emergência - a cominação com o crime de desobediência tem sido o mecanismo de tutela penal para as diversas violações de deveres impostos aos cidadãos, aumentando significativamente a relevância e o impacto desta incriminação em contexto pandémico e fazendo colocar a questão de "se e como deve o direito penal ser instrumento no cumprimento de deveres excecionalmente impostos em situação de emergência" (14).

Por outro lado, e ainda a propósito deste crime, tendo mesmo a sua inserção no Código Penal português sido, ao tempo, contestada (12, p. 350) (15, p. 133), não deixa de ser um sinal de alerta uma via repressiva assente na expansão do crime de desobediência, que evidencia os perigos do recurso a estados de exceção e da tendência centrípeta do poder repressivo do Estado.

Pensamos, pois, atentas as diversas previsões de especialistas de que os ciclos pandémicos serão mais frequentes, dever-se acentuar, por um lado, a necessidade de uma efetiva tutela penal da saúde pública e, por outro lado, a existência de vantagem na consagração de leis específicas - como na RAEM - que possam contribuir para uma melhor definição das margens de punibilidade, evitando o recurso a normas penais em branco.

Só assim sendo possível um direito penal justo, mesmo em contexto pandémico. 
14. Sousa SA. Saúde pública, direito penal e "abate clandestino". [citado em 5 mar. 2021]. Disponível em: https://www.uc.pt/covid19/article?key=a-6eb8a5985f

15. Vilela A. COVID-19 e o Direito Penal. In: COVID 19 e o Direito, Lisboa: Edições Universitárias Lusófonas; 2020

Como citar este artigo

Godinho IF. Direito Penal e COVID-19 no espaço lusófono. Cadernos Ibero-Americanos de Direito Sanitário. 2021 abr./jun.;10(2):139-150

https://doi.org/10.17566/ciads.v10i2.797 